\title{
LETRAMENTO DIGITAL E FORMAC̣ÃO DE PROFESSORES
}

\section{Maria Teresa Freitas*}

RESUMO: Este artigo aborda o letramento digital no interior da discussão sobre a formação de professores, reportando-se às experiências construídas em um grupo de pesquisa orientado pela perspectiva psicológica histórico-cultural. Apresentadas algumas definições de letramento digital, reflete-se sobre os desafios postos à escola pelo confronto com as novas práticas de leitura e escrita propiciadas pelos usos do computador e da internet. Em seguida, analisa-se como, em sua formação inicial e continuada, os professores são preparados para a inserção dessas tecnologias em suas práticas pedagógicas e para compreenderem o letramento digital de seus alunos. Ao final, situa-se o professor na era da internet, em seu lugar insubstituível de mediador e problematizador do conhecimento, que adota uma posição aberta e ao mesmo tempo crítica diante do que essa tecnologia digital oferece.

Palavras-chave: Letramento Digital; Escola; Formação de Professores.

\section{DIGITAL LITERACY AND TEACHER TRAINING}

ABSTRACT: This article has approached the digital literacy in the internal discussion on teacher training, reporting the experiences constructed in a research group guided through the psychological historical-cultural perspective. Having presented some definitions of digital literacy, we could reflect upon the challenges posed to the educational system by the confrontation with new reading and writing practices made possible by the use of computers and the internet. Next, we analyzed how teachers, in their initial and continued training program, are prepared to the insertion of these technologies in their pedagogical practices and how to understand their student's digital literacy. At the end, teachers are placed in the internet age, in their irreplaceable task as knowledge mediator and questioner, adopting an open position, and, at the same time, a critical one, on the face of what this digital technology offers.

Keywords: Digital Literacy; School; Teacher Training.

\footnotetext{
* Doutora em Educação pela Pontifícia Universidade Católica do Rio de Janeiro (PUC-RJ); Professor associado II da Universidade Federal de Juiz de Fora (UFJF) e Pesquisadora do Conselho Nacional de Desenvolvimento Científico e Tecnológico (CNPq). Email: mt|@acessa.com
} 


\section{Introduzindo o tema}

O tema do letramento digital pode ser tratado a partir de diferentes focos. Optei por abordá-lo no interior da discussão sobre a formação de professores. É esse o foco das pesquisas desenvolvidas pelo Grupo de Pesquisa Linguagem Interação e Conhecimento (LIC), por mim coordenado na Faculdade de Educação da UFJF. Inicialmente, as pesquisas do grupo foram voltadas para a relação de professoras de ensino fundamental e médio, em exercício e aposentadas, com a leitura-escrita (1995-1997)', e, depois, focalizaram as práticas socioculturais de leitura e escrita de crianças e adolescentes (1997-1999)2. Os achados dessa segunda pesquisa revelaram a existência, na vida do grupo pesquisado, de práticas diferenciadas de leitura e escrita, em interação com diversos instrumentos culturais da contemporaneidade, destacando-se aí o uso do computador e da internet. Assim, surgiu, para o grupo LIC, um novo e instigante objeto de pesquisa: o letramento digital de adolescentes, que se configurou em uma terceira pesquisa (1999-2001), ${ }^{3}$ na qual procurou-se compreender a leitura-escrita de adolescentes em chats e também em e-mails, a partir de listas de discussão sobre dois seriados televisivos: Friends e Charmed.

Esse momento marcou o início de uma nova direção tomada pelo grupo em seus estudos. Continuando a ter a linguagem como centro do trabalho e a focalizar a escola com seus atores e sua formação, nosso interesse voltou-se especificamente para a questão do letramento digital, dos usos do computador e da internet, tema inesgotável, que gerou diferentes recortes e abordagens nas três pesquisas subsequentes. Assim, de 2001 a 2003, foram estudados sites construídos por adolescentes ${ }^{4}$. Esse mergulho no letramento digital de adolescentes provocou o movimento de se buscar compreender como a escola e os professores se situavam em relação a essa leitura-escrita de seus alunos. Nesse sentido, a pesquisa desenvolvida de 2003 a $2006^{5}$ incidiu sobre a formação continuada de professores, buscando conhecer o letramento digital de docentes e confrontando-o com o letramento digital de seus alunos. A partir de $2006^{6}$, até o momento atual, os esforços de pesquisa do Grupo LIC se centraram na formação inicial e continuada de professores, procurando relações entre o letramento digital e a aprendizagem, e suas implicações no processo pedagógico.

As experiências construídas nessas pesquisas, orientadas pelo enfoque teórico da abordagem histórico-cultural, foram fundamentais 
para a compreensão do computador e da internet como instrumentos culturais de aprendizagem ${ }^{7}$. Partindo dos conceitos de instrumentos materiais (ferramentas) e instrumentos psicológicos (signos) propostos por Vygotsky (1991), compreendo que essas tecnologias são, ao mesmo tempo, instrumento técnico e simbólico (FREITAS, 2009a). Além de máquinas, são instrumentos de linguagem que exigem, para seu acesso e uso, diferentes e novas práticas de leitura-escrita. De modo geral, todos os usos do computador-internet se processam a partir da leitura-escrita e da presença cada vez mais intensa de recursos multissemióticos, multimidiáticos e hipermidiáticos nessa tecnologia. A própria inserção do computador-internet no processo pedagógico acontece, principalmente, a partir de trabalhos realizados via ambientes virtuais de aprendizagem (AVA), fóruns de discussão, e-mails, blogs, sites de busca, para viabilizar pesquisas, wiki, etc., atividades essas que passam, necessariamente, pelo letramento digital. Portanto, é relevante e urgente uma discussão do letramento digital no trabalho com professores, tema principal deste artigo.

\section{Letramento digital}

Mas, o que é o letramento digital? Preocupada com uma melhor compreensão desse termo, apresento aqui um interessante levantamento, organizado por Souza (2007), de diferentes definições de letramento digital, classificando-as em dois tipos: definições restritas e amplas.

A autora entende que as definições restritas não consideram o contexto sociocultural, histórico e político que envolve o processo de letramento digital. São definições mais fechadas em um uso meramente instrumental. Entre as definições restritas citadas pela autora seleciono duas que exprimem bem essa ideia. A primeira refere-se ao relatório Digital Transformation", no qual letramento digital é definido como "usar a tecnologia digital, ferramentas de comunicação e/ou redes para acessar, gerenciar, integrar, avaliar e criar informação para funcionar em uma sociedade de conhecimento" (SERIM, 2002 citado por SOUZA, 2007, p. 57).

A segunda foi elaborada pela Association of College \& Research Libraries e define letramento digital como "uma série de habilidades que requer dos indivíduos reconhecer quando a informação faz-se necessária 
e ter a habilidade de localizar, avaliar e usar efetivamente a informação necessária” (CESARINI, 2004, s/p citado por SOUZA, 2007, p. 57).

Antes de apresentar as definições mais amplas, que tomam o letramento digital como prática social culturalmente constituída, Souza (2007) traz um pertinente comentário, feito por Smith (2000), de que cada vez se torna mais difícil e complexo determinar quem é letrado no meio digital. Ser letrado digital inclui, além do conhecimento funcional sobre o uso da tecnologia possibilitada pelo computador, um conhecimento crítico desse uso. Assim, tornar-se digitalmente letrado significa aprender um novo tipo de discurso e, por vezes, assemelha-se até a aprender outra língua.

As definições de letramento digital mais amplas supõem esses aspectos ao não prescindirem dos sentidos social e cultural. Entre as apresentadas por Souza (2007), seleciono estas: letramento digital se constitui como "uma complexa série de valores, práticas e habilidades situados social e culturalmente envolvidos em operar lingüisticamente dentro de um contexto de ambientes eletrônicos, que incluem leitura, escrita e comunicação (SELFE, 1999, p. 11 citado por SOUZA, 2007, p. 59). Nessa definição, letramento digital refere-se aos contextos social e cultural para discurso e comunicação, bem como aos produtos e práticas linguísticos e sociais de comunicação, e os modos pelos quais os ambientes de comunicação têm se tornado partes essenciais de nosso entendimento cultural do que significa ser letrado.

Indicando as competências básicas para o processo de letramento digital, Gilster (1997) formula a definição: "habilidade de entender e usar informação em formatos múltiplos de uma vasta gama de fontes quando esta é apresentada via computadores" (GILSTER, 1997, p. 1 citado por SOUZA, 2007, p. 60). Ele enfatiza que as ferramentas disponíveis no meio digital estão relacionadas a aprender a lidar com ideias, e não a memorizar comandos. $\mathrm{O}$ autor sugere a proficiência em quatro competências básicas para a aquisição de letramento digital. A mais essencial delas é a avaliação crítica de conteúdo, ou seja, a habilidade de julgar o que encontramos na rede. A segunda competência é a de ler usando o modelo não-linear ou hipertextual. Além disso, faz-se necessário aprender como associar as informações dessas diferentes fontes, isto é, a construção de conhecimento diante da internet. Finalmente, é importante desenvolver habilidades de buscas para lidar com o que ele denomina "biblioteca virtual” (GILSTER, 1997, p. 155 citado por SOUZA, 2007, p. 60). 
Lankshear e Knobel (2005 citado por SOUZA, 2007) criticam a visão de letramento digital como uma série idealizada de competências e habilidades específicas, algo único e mensurável. A proposta deles baseiase na ideia de plural, ou seja, de "letramentos digitais". Letramentos digitais constituem formas diversas de prática social que emergem, evoluem, transformam-se em novas práticas e, em alguns casos, desaparecem, substituídas por outras.

As discussões e os estudos sobre letramento digital vêm crescendo no Brasil e, nesse sentido, considero muito importante, por sua qualidade inaugural, o texto de Magda Soares intitulado "Novas Práticas de Leitura e Escrita: Letramento na Cibercultura" (2002). Esse texto segue a linha apontada por Lankshear e Knobel (2005) sobre a ideia de letramentos e sua definição se enquadra entre as apontadas por Souza (2007) como definições ampliadas. Soares (2002) define letramento digital como "certo estado ou condição que adquirem os que se apropriam da nova tecnologia digital e exercem práticas de leitura e de escrita na tela diferentes do estado ou condição - do letramento - dos que exercem práticas de leitura e de escrita no papel" (p. 151). Partindo dessa definição e das reflexões feitas no texto sobre leitura e escrita na cibercultura, a autora sugere que se "pluralize a palavra letramento e se reconheça que diferentes tecnologias de escrita criam diferentes letramentos" (2002, p. 155). Indica, em seguida, que essa necessidade de pluralização da palavra letramento já vinha sendo reconhecida internacionalmente, citando vários autores, estando entre eles Lankshear.

Buzato, outro autor brasileiro envolvido com as questões do letramento digital, apresenta uma definição que pode também ser incluída entre as ampliadas:

Letramentos digitais (LDs) são conjuntos de letramentos (práticas sociais) que se apóiam, entrelaçam e apropriam mútua e continuamente por meio de dispositivos digitais para finalidades específicas, tanto em contextos socioculturais geograficamente e temporalmente limitados, quanto naqueles construídos pela interação mediada eletronicamente. (BUZATO, 2006, p. 16)

A partir do exposto, compreendo letramento digital como o conjunto de competências necessárias para que um indivíduo entenda e use a informação de maneira crítica e estratégica, em formatos múltiplos, vinda de variadas fontes e apresentada por meio do computador-internet, 
sendo capaz de atingir seus objetivos, muitas vezes compartilhados social e culturalmente.

Essa discussão sobre o termo letramento digital é trazida aqui para situar o tema e mostrar a sua importância para a formação de professores.

\section{Formação de professores diante do letramento digital}

Quando se diz que os professores devem ser letrados digitais, essa afirmação se baseia em uma definição restrita ou ampliada? Referese à possibilidade de acesso a esses instrumentos ou ao domínio de capacidades básicas para o seu uso? Acesso e uso instrumental fazem-se importantes, mas não atingem o que se espera, de fato, dos professores. Tenho observado, por meio de nossas pesquisas, que escolas equipadas com computadores e acesso à internet e professores egressos de cursos básicos de informática educativa não têm sido suficientes para que se integrem os recursos digitais e as práticas pedagógicas. Se o desejável é que os professores integrem computador-internet à prática profissional, transformando-a para melhor inseri-la no contexto de nossa sociedade marcada pelo digital, é preciso ir muito além. Os professores precisam conhecer os gêneros discursivos e linguagens digitais que são usados pelos alunos, para integrá-los, de forma criativa e construtiva, ao cotidiano escolar. Quando digo integrar é porque o que se quer não é o abandono das práticas já existentes, que são produtivas e necessárias, mas que a elas se acrescente o novo. Precisamos, portanto, de professores e alunos que sejam letrados digitais, isto é, professores e alunos que se apropriam crítica e criativamente da tecnologia, dando-lhe significados e funções, em vez de consumi-la passivamente. O esperado é que o letramento digital seja compreendido para além de um uso meramente instrumental.

A experiência com as pesquisas desenvolvidas no grupo de pesquisa LIC tem me proporcionado a compreensão de que a tarefa das escolas e dos processos educativos é desenvolver novas formas de ensinar e aprender, em razão das exigências postas pela contemporaneidade. A revolução tecnológica introduz não só uma quantidade enorme de novas máquinas, mas principalmente um novo modo de relação entre os processos simbólicos que constituem o cultural. De acordo com Martín-Barbero (2006), 
o lugar da cultura na sociedade muda quando a mediação tecnológica da comunicação deixa de ser meramente instrumental para espessar-se, condensar-se e converter-se em estrutural: a tecnologia remete, hoje, não a alguns aparelhos, mas, sim, a novos modos de percepção e de linguagem, a novas sensibilidades e escritas (MARTÍN-BARBERO, 2006, p. 54).

$\mathrm{Na}$ rede informacional que nos envolve, misturam-se vários saberes e formas muito diversas de aprender, enquanto nosso sistema educativo ainda se encontra todo organizado em torno da escola e do livro. O que estamos vivendo hoje, segundo Martín-Barbero (2006), é uma transformação nos modos de circulação do saber, que, disperso e fragmentado, circula fora dos lugares sagrados que antes o detinham e das figuras sociais que o geriam. Portanto, a escola está deixando de ser o único lugar da legitimação do saber, o que se constitui em um enorme desafio para o sistema educativo. Diante desse desafio, muitas vezes os docentes adotam uma posição defensiva e às vezes até negativa, no que se refere às mídias e às tecnologias digitais, como se pudessem deter seu impacto e afirmar o lugar da escola e o seu como detentores do saber. É preciso que, perante essa nova ordem das coisas, a escola e seus profissionais não se afastem, mas busquem compreender o que se passa e se disponham a interagir com as novas possibilidades. É o que nos aponta Bakhtin, ao refletir sobre a necessidade de diálogo entre duas culturas.

A cultura do outro só se revela com plenitude e profundidade [...] aos olhos de outra cultura. Um sentido só revela as suas profundidades encontrando-se e contactando com outro, com o sentido do outro: entre eles começa uma espécie de diálogo que supera o fechamento e a unilateralidade desses sentidos, dessas culturas. Colocamos para a cultura do outro novas questões que ela mesma não se colocava; nela procuramos respostas a essas questões, e a cultura do outro nos responde, revelando-nos seus novos aspectos, novas profundidades de sentido. Sem levantar nossas questões não podemos compreender nada do outro de modo criativo.[...] Neste encontro dialógico de duas culturas elas não se confundem; cada uma mantém a sua unidade e a sua integridade aberta, mas elas se enriquecem mutuamente. (BAKHTIN, 2003, p. 366)

É esse o espírito que nos move nas pesquisas que o grupo LIC desenvolve procurando compreender essas duas culturas: professores ("estrangeiros digitais") e alunos ("nativos digitais"), que se defrontam e se confrontam com experiências diversas em relação às tecnologias digitais. 
De nossa última pesquisa, em fase de finalização, retiro algumas reflexões efetuadas a partir do desenvolvimento de um de seus subprojetos. Esse subprojeto foi realizado com um grupo de sete professores da Faculdade Educação da UFJF, que trabalham com as disciplinas do curso de Pedagogia e demais licenciaturas e que, no momento, estão desenvolvendo em seus cursos presenciais atividades que incluem diferentes usos do computador-internet. Esses docentes participaram no processo da pesquisa de encontros de grupos focais reflexivos coordenados por pesquisadores do grupo LIC. Analisando o processo discursivo que se estabeleceu nesses encontros, materializado nos enunciados trocados entre os participantes, pude observar interessantes aspectos, compreendendo como esses professores se situam em relação ao uso das tecnologias digitais no processo pedagógico, suas relações com a aprendizagem e como se percebem como formadores de professores de uma geração digital.

Contextualizando esse grupo de professores, posso dizer que, em sua maioria, eles se aproximaram das tecnologias digitais, começando a utilizá-las no ensino presencial a partir de suas experiências com a EaD (Educação a Distância), principalmente depois de seu envolvimento com a Universidade Aberta do Brasil (UAB) ${ }^{9}$. Apenas poucos professores mostraram que sua integração com as tecnologias digitais era mais antiga, fazendo parte de sua história de vida pessoal, e como isso facilitou seu uso também no plano profissional. Outros estão se iniciando agora no trabalho com as tecnologias digitais em suas salas de aula presenciais e mostram-se entusiasmados e interessados em relação aos trabalhos que desenvolvem com seus alunos, utilizando a plataforma Moodle. Alguns poucos se mostram mais reticentes, preocupados com aspectos ligados à exclusão digital, à dificuldade grande de uso e acesso por parte de alunos de escolas públicas, aos problemas de acessibilidade no Infocentro da Faculdade de Educação, a extensão do tempo gasto por professores e alunos para participarem de ambientes on-line.

Ficaram visíveis as dificuldades, dúvidas e incertezas diante desse uso, como também a satisfação encontrada pelas experiências obtidas ao trabalharem com fóruns de discussão e outros recursos da plataforma Moodle. Consideraram que os recursos on-line, ao serem introduzidos na dinâmica do ensino presencial, ampliam o espaço da sala de aula e os alunos se sentem envolvidos em buscar outras fontes e recursos para alimentar as discussões nos fóruns. Destacaram as possibilidades que esse novo 
ambiente traz para o processo de ensino e aprendizagem, prolongando a reflexão e o desenvolvimento da capacidade argumentativa dos seus usuários. Foi muito interessante observar o consenso da posição dos participantes quanto ao papel da escrita na internet. $\mathrm{Na}$ realidade, foi apontado que o computador e a internet oferecem uma pluralidade de espaços e de meios que poderiam levar a novas formas de aprendizagem, como o som, a imagem, o movimento, a animação, o vídeo, etc. Mas tudo isso ainda é de muito difícil acesso para todos. Nesse sentido, foram questionadas as dificuldades de acesso ao Infocentro da Faculdade de Educação, que não está aberto para uso didático dos professores e que não permite trabalhos que necessitam do som e de acesso a sites que são bloqueados pelo provedor, como também a dificuldade de serem feitos downloads de vídeos. Essas dificuldades restringem os trabalhos on-line apenas ao material escrito. Assim, o real, o que é possível, no espaço estudado, é a produção textual, a escrita.

O que faz diferença nessa escrita digital? Foram apontados aspectos como a sincronia, a escrita que se converte em memória, a possibilidade de ser lida e relida. A escrita on-line, em seu processo de uso, favorece uma produção textual gradativamente mais consistente, desenvolvida a partir da exploração de temas tratados no presencial e que ganham visibilidade no ambiente virtual de aprendizagem. Dificuldades foram apontadas em relação a uma escrita coletiva construída no wiki, devido aos receios dos alunos de interferirem no texto do outro. A pesquisa escolar, facilitada e aviltada com o copiar-colar, com o plágio, que é tão fácil a partir da internet, também esteve presente nas discussões, salientando-se que, na maioria das vezes, os alunos não são orientados pelos professores para fazerem uma busca crítica de informações.

Os enunciados trocados nos grupos focais reflexivos levantaram questões e trouxeram possibilidades de reflexão. O professor como aprendente e seu novo papel no processo de aprendizagem a partir da construção de um letramento digital, como um conhecimento necessário, foram os pontos nodais para uma reflexão que se provocou, se iniciou e deve ser continuada. O que trago, neste artigo, é apenas uma parcela, uma ponta do iceberg do que aconteceu durante os grupos focais reflexivos. Esse material ainda está sendo analisado e, aí sim, teremos uma visão mais completa de como esses docentes se situam no enfretamento com a inserção dos recursos da tecnologia digital no processo pedagógico e na formação de professores. 
Desejamos que, com esta pesquisa, se instaure, nos processos formativos empreendidos pelos professores investigados, um espaço de reflexão sobre essas questões. Estima-se que se possa levar à construção de uma posição responsável e consequente diante da integração do computador-internet na escola como instrumento cultural de aprendizagem.

Isso é importante, uma vez que, nos processos formativos de professores, tanto iniciais quanto continuados, ainda se mostram tímidos os esforços de trabalho relacionados ao letramento digital. Isso se torna visível em um relatório de pesquisa publicado recentemente: Professores do Brasil: impasses e desafios (GATTI; BARRETO, 2009). Essa pesquisa teve como objetivo oferecer um balanço da situação relativa à formação de professores para a educação básica no Brasil. Entre outros aspectos focalizados, o trabalho investigativo analisou a estrutura curricular e as ementas de 165 cursos presenciais de instituições de ensino superior do país, responsáveis pela formação inicial de docentes nas áreas de Pedagogia, Letras: Língua Portuguesa, Matemática e Ciências Biológicas. Em relação ao Curso de Pedagogia, as pesquisadoras, em uma síntese dos resultados encontrados, indicam, entre outros aspectos citados, que o currículo do curso tem uma característica fragmentária, apresentando um conjunto de disciplinas bastante disperso, no qual não se faz presente, de forma concreta, a relação teoria-prática. As autoras concluem que, nesse sentido: "A escola, enquanto instituição social e de ensino, é elemento quase ausente nas ementas, [das disciplinas] o que leva a pensar numa formação de caráter mais abstrato e pouco integrado ao contexto concreto onde o profissional-professor vai atuar" (GATTI; BARRETO, 2009, p. 153).

Percebo, observando os dados da pesquisa apresentados, que essa falta de integração ao contexto concreto também se manifesta na ausência de disciplinas focalizando a temática dos usos do computadorinternet na prática pedagógica. O que foi apurado é que a parte curricular, que propicia o desenvolvimento de habilidades profissionais específicas para a atuação nas escolas e nas salas de aula, se apresenta muito reduzida. As disciplinas optativas, que ocupam $25 \%$ em relação ao total das disciplinas, se referem a outros saberes, além dos específicos, próprios da área de estudo, e apresentam grande variação temática. Nesse rol de variedades, há 3,2\% de disciplinas preocupadas com os desafios postos pela era da informática, o que considero como algo ainda muito incipiente. Além disso, ao focalizarem as novas tecnologias, a educação a distância ou a 
inclusão digital, o fazem a partir de estudos mais teóricos, não chegando à prática. Nesse sentido, percebo que não há preocupação com o letramento digital especificamente. Estuda-se sobre a informática na educação, mas não se forma o futuro professor, trabalhando seu letramento digital ou envolvendo-o em atividades de efetivo uso do computador-internet como instrumentos de aprendizagem. Debruçando-me sobre os dados e as análises dessa pesquisa, chego a pensar que essa aproximação com o letramento digital não deve ser feita, necessariamente, a partir de determinada disciplina, mas por meio de um trabalho contínuo, no interior de todas as disciplinas nas quais o professor, em sua formação inicial, possa experienciar o letramento digital no próprio processo pedagógico.

Continuando a reflexão sobre a pesquisa desenvolvida por Gatti e Barreto (2009), busco como as autoras se referem às demais licenciaturas: Língua Portuguesa, Matemática e Ciências Biológicas. A análise dos currículos dessas licenciaturas evidenciou, entre outros aspectos assinalados, a predominância de uma formação disciplinar específica, em detrimento da formação de professores para essas áreas do conhecimento. Como as questões vinculadas às tecnologias digitais e seu uso no ensino são contempladas nos currículos dessas licenciaturas?

Nos currículos das licenciaturas em Língua Portuguesa, há indicações de disciplinas que focalizam a tecnologia aplicada à educação ou os recursos tecnológicos aplicados ao ensino de Português. Do total de disciplinas relacionadas aos conhecimentos específicos para a docência, 2,4\% se referem aos saberes ligados à tecnologia.

Em relação aos currículos dos cursos de licenciatura em Matemática, nas disciplinas que reúnem conhecimentos específicos para a docência, observa-se uma preocupação em fornecer um instrumental para a atuação do profissional de Matemática como professor. Entre elas, há as que abordam os saberes relacionados à tecnologia em enfoque de utilização, que incorporam os seguintes temas: Aplicações da informática para o ensino da Matemática; Computação para o ensino; Tecnologias da informação e comunicação; Aplicações à Educação Matemática (GATTI; BARRETO, 2009). Entre os currículos e as ementas analisados no âmbito das licenciaturas em Matemática, as pesquisadoras verificam que:

Apenas um deles não possui uma disciplina específica para trabalhar com conceitos ligados à computação. Porém quando se trata de uso da informática para a educação, esta é referida claramente em apenas $29 \%$ dos cursos. Três 
dos cursos apresentam várias disciplinas com ementas que fazem referência às novas tecnologias de informação e comunicação. Observa-se, no entanto, que as ementas mostram mais uma discussão sobre a utilização dessas tecnologias do que sua aplicação propriamente dita. Questiona-se se a forma como este conhecimento vem sendo ministrado favorece a utilização das novas tecnologias nas práticas de ensino dos futuros professores. Ou seja, se disciplinas que apenas discutem, teoricamente, a informática no ensino e que fornecem fundamentos da computação são suficientes para uma futura prática docente com utilização das novas tecnologias (GATTI; BARRETO, 2009, p. 144).

Nos currículos das licenciaturas em Ciências Biológicas, apenas $2,1 \%$ das disciplinas se referem a saberes relativos às tecnologias. Quanto às ementas analisadas, em nenhuma delas se observou a articulação com as novas tecnologias para mediação na educação científica.

Numa síntese das análises feitas em relação às licenciaturas de Língua Portuguesa, Matemática e Ciências Biológicas, as autoras indicam, entre outros achados, que predomina nos currículos a formação disciplinar específica, em detrimento da formação de professores para essas áreas do conhecimento, e que os saberes relacionados às tecnologias digitais no ensino estão praticamente ausentes.

Diante desses dados e das análises apresentadas, percebo como a formação inicial de professores ainda está distante de enfrentar computador e internet como instrumentos de aprendizagem. As porcentagens que indicam a presença de disciplinas sobre tecnologias nos currículos dos cursos analisados, por si só, mostram que esse é um esforço ainda muito pequeno. A análise dessas ementas são ainda mais eloquentes para dizerem que o futuro professor não está sendo capacitado para utilizar, em sua docência, os recursos do computador-internet. Pela nomenclatura das disciplinas e pelo conteúdo que abordam, percebe-se que há preocupação com as tecnologias em si, mas não com o letramento digital do professor em formação.

Um fato interessante é que essa pesquisa também se ocupou em olhar para os estudantes universitários das carreiras que conduzem à docência. Procurou situá-los quanto a suas escolhas, idade, sexo, situação econômica, bagagem cultural, domínio de língua estrangeira, consumo cultural e também usos do computador. Vou me reportar apenas a esse último item por ser o que se correlaciona mais diretamente ao objetivo deste texto. 
As respostas dos estudantes universitários pesquisados informam que apenas 5\% dos alunos não utilizam computador e $63,7 \%$ o utilizam com muita frequência; 81,3\% têm acesso à internet e 87,6\% consideram que têm bom domínio de informática (GATTI; BARRETO, 2009). No entanto, os estudantes indicam que, nas instituições nas quais realizam suas graduações, há limitações para os usos do computador-internet. Apenas 28,5\% afirmam ter pleno acesso a essas tecnologias, enquanto $52 \%$ as utilizam com limitações. Segundo as autoras, os demais não utilizam computadores em suas faculdades, por sua inexistência, por não estarem disponíveis ou porque consideram que o curso não necessita desses tipos de recursos.

Essas constatações são preocupantes e assinalam a distância entre o letramento digital dos alunos e o que lhes é oferecido, sob esse aspecto, em seu processo de formação nas instituições. Isso fica mais evidente quando esses dados são cruzados com as estratégias de ensino presentes nos cursos analisados. O que aparece é a predominância absoluta de aulas expositivas, sendo também observados trabalhos de grupo, em alguns poucos cursos. As autoras chamam a atenção para o extremo desequilíbrio encontrado nos curso de formação docente entre as abundantes aulas expositivas e a absoluta escassez de aulas práticas, em todos os cursos. Assim exprimem-se as autoras em sua análise:

[....] um curso feito a base de apostilas e resumos e cópias de trechos ou capítulos de livros é basicamente o que forma a maioria dos estudantes para o magistério, quer nos cursos de Pedagogia, quer nos das demais licenciaturas! Esse o tipo de material mais usado pelos alunos, segundo $67 \%$ das respostas (GATTI; BARRETO, 2009, p. 175).

Com essa formação, como atender às demandas da nova sociedade da informação? Como preparar professores para enfrentarem o letramento digital de seus futuros alunos? Como formar professores para um ensino efetivo, se o conhecimento é trabalhado nessas instituições à margem das novas possibilidades que computador-internet trazem para seus usuários? São reflexões que se impõe diante do quadro apresentado. 


\section{0 professor na era da internet}

Retomando o que já foi dito neste artigo sobre o letramento digital dos nativos digitais, considero importante assinalar que esse letramento lhes permite acesso maior às informações. Hoje, o aluno traz para a escola o que descobriu em suas navegações de internauta e está disposto a discutir com seus colegas e com o professor. Ele não vê mais o professor como um transmissor ou a principal fonte de conhecimento, mas espera que ele se apresente como um orientador das discussões travadas em sala de aula ou mesmo nos ambientes on-line integrados às atividades escolares. A possibilidade de pesquisar, ler e conhecer sobre os mais variados assuntos navegando na internet confere ao aluno um novo perfil de estudante, que exige também novo perfil de professor. Cabe ao professor estar atento a essa nova fonte de informações para transformá-las, junto com os alunos, em conhecimento. Essa é uma das características do letramento digital: associar informações, ter uma perspectiva crítica diante delas, transformando-as em conhecimento. O professor é parte inerente e necessária a todo esse processo, em seu lugar insubstituível de mediador e problematizador do conhecimento, um professor que também aprende com o aluno.

Aqui uma pergunta se impõe: um professor que pertence a outra cultura, um estrangeiro digital, como pode se situar diante do aluno, um nativo digital? Retorno aqui às palavras de Bakhtin sobre o diálogo entre duas culturas. Para o autor, elas, em um movimento dialógico, não perdem sua identidade e não se confundem, mas podem se enriquecer mutuamente ao se colocarem abertas para mútuas aprendizagens. Essa abertura poderá possibilitar aos educadores um novo olhar para si mesmos e para o outro, que tem uma visão de mundo diferente da sua. Nesse sentido, é importante que educadores (e eu me coloco nesse lugar) comecem a reconhecer que o aluno nativo digital tem um conhecimento específico que nós não temos: ele tem um letramento digital no sentido amplo, e não apenas um domínio técnico. Como falta ao professor o letramento digital e ele não reconhece esse letramento digital do aluno como conhecimento, mas como técnica, o professor também não se reconhece como um não-letrado digital. Como não temos esse conhecimento, precisamos realizar o movimento de aprender com o aluno que o detém. Aqui, lembro uma instigante frase de Pasolini, em seu livro Jovens infelizes: "Não se pode ensinar se ao mesmo tempo não se aprende" (1990, p. 132). 
Situo, assim, o papel do professor na contemporaneidade como formador de novos docentes, que terão como alunos nativos digitais. Formação que deve ter uma ancoragem consistente na epistemologia do conhecimento, compreendendo-o como algo provisório e transitório, mas que tem regras e rigor. Ou seja, o educador é aquela pessoa que tem de estar sempre aberta ao novo, para investigá-lo e ver o que ele representa para o conhecimento e para a aprendizagem. Para formar futuros professores para o trabalho com nativos digitais faz-se necessário enfrentar a responsabilidade de uma constante atualização, a defasagem entre o seu letramento digital e o do aluno, e manter o distanciamento possibilitador de um olhar crítico diante do que a tecnologia digital oferece. Assim, espera-se que, nessa era da internet, o professor possa fazer de sua sala de aula um espaço de construções coletivas, de aprendizagens compartilhadas. 


\section{Referências}

BAKHTIN, M. Os estudos literários hoje. In: BAKHTIN, M. Estética da criação verbal. São Paulo: Martins Fontes, 2003. p. 358-366.

BUZATO, M. E. K. Letramentos digitais e formação de professores. São Paulo: Portal Educarede. 2006. Disponível em: <http://www.educarede.org.br/educa/img_conteudo/marcelobuzato.pdf $>$. Acesso em: 2 jul. 2009.

CESARINI, P. Computers, technology and literacies. Journal of Literacy and Technology, v. 4, 2004. Disponível em: <http://www.literacyandtechnology.org/v4/pfvs/pfv_cesarini.htm>. Acesso em: 10 maio 2006.

FERNANDES, O. P.; FREITAS, M. T. A. A Presença ausente do computador/Internet na Formação do Pedagogo. Educação em Foco. Juiz de Fora: FEME, v. 10, n. 1 e n. 2 p. 195-218, mar./ago. 2005, set./fev. 2005/2006.

FREITAS. M. T. A.; COSTA, S. R. (Orgs.). Leitura e escrita na formação de professores. S. Paulo/Juiz de Fora: Musa/EDUFJF/Comped, 2002.

FREITAS, M. T. A.; COSTA, S. R. (Orgs.). Leitura e escrita de adolescentes na internet e na escola. Belo Horizonte: Autêntica, 2005.

FREITAS, M. T. A. (Org.). Narrativas de professoras - pesquisando leitura e escrita numa perspectiva sócio-histórica. Rio de Janeiro: Ravil, 1998.

FREITAS, M. T. A. Memórias de professoras: História e histórias. São Paulo/Juiz de Fora: Musa/EDUFJF, 2001.

FREITAS, M. T. A. Letramento digital e a formação de professores. $28^{a}$ Reunião Anual da Associação Nacional de Pós-Graduação e Pesquisa em Educação / 40 anos da PósGraduação em Educação no Brasil. Caxambu, Anais... CD-ROM, 2005a.

FREITAS, M. T. A. Sites construídos por adolescentes: novos espaços de leitura-escrita e subjetivação. Cadernos CEDES (UNICAMP), v. 1, p. 87-101, 2005b.

FREITAS, M. T. A. Formação de professores e o uso do Computador e da internet na escola. Educação em Foco. Juiz de Fora: Feme, v. 12, n. 12, p. 251-270, dez. 2007/fev. 2008. FREITAS, M. T. A. Computador/internet como instrumentos de aprendizagem: uma reflexão a partir da abordagem psicológica histórico-cultural. SIMPÓSIO HIPERTEXTO E TECNOLOGIAS NA EDUCAÇÃO MULTIMODALIDADE E ENSINO, Anais... 2, 2008, Recife. Anais eletrônicos... Recife, 2008. Disponível em: <http://www.ufpe.br/nehte/simposio2008/anais/Maria-Teresa-Freitas.pdf>. Acesso em: 15 jul. 2009.

FREITAS, M. T. A. Janela sobre a utopia: computador e internet a partir do olhar da abordagem histórico-cultural. 32a . Reunião Anual da Associação Nacional de Pós Graduação e pesquisa em Educação. Anais... CD-ROM. Caxambu, 2009.

GATTI, B. A.; BARRETO. E. S. S. (Orgs.) Professores do Brasil: impasses e desafios. Brasília: Unesco, 2009.

GILSTER, P. Digital literacy. New York: John Wiley \& Sons, Inc., 1997.

LANKSHEAR, C.; SNYDER, I. Teachers and Technoliteracy, managing literacy, technology and learning in schools. St Leonards: Allen \& Unwin, 2000.

MARTÍN-BARBERO, J. Tecnicidades, identidades, alteridades: mudanças e opacidades da comunicação no novo século. In: MORAES, D. Sociedade midiatizada. Rio de Janeiro: Mauad X, 2006, p. 51-79.

PASOLINI, P. P. Os jovens Infelizes. São Paulo: Brasiliense, 1990. 
SELFE, C. L. Technology and literacy in the twenty-first century: the importance of paying attention. Chicago: Southern Illinois University Pres, 1999.

SERIM, F. The importance of contemporary literacy in the digital age: a response to digital transformation: a framework for information communication technologies (ICT) literacy. Mensagem postada em The Big 6: information skills for student achievement em 10 mai. 2002. Disponível: <http://www.big6.com/showarticle.php?id=157>. Acesso em: 12 mai. 2006.

SMITH, A. From the feel of the page or the touch of a button: envisioning the role of digital technology in the English and language arts classroom. Spring, 2000. Disponível em: <http://www.msu.edu/ smitha62/computer.htm>. Acesso em: 10 abr. 2006.

SOARES, M. Novas práticas de leitura e escrita: letramento na cibercultura. Educação e Sociedade, Campinas, v. 23, n. 81 p. 143-160, dez. 2002.

SOUZA, V. V. Soares. Letramento digital e formação de professores. Revista Lingua Escrita, n. 2, p. 55-69, dez. 2007.

VYGOTSKY, L. S. A formação social da mente. São Paulo: Martins Fontes, 1991.

\section{Notas}

1 Pesquisa intitulada "Cultura, Modernidade e Linguagem: leitura e escrita de professores em suas histórias de vida e formação” (1995 -1997), financiada pelo CNPq e pela Fapemig. O conhecimento produzido nessa pesquisa foi publicado em dois livros: FREITAS, M.T. A (Org.) Narrativas de professoras - pesquisando leitura e escrita numa perspectiva sócio-histórica. Rio de Janeiro: Ravil, 1998. FREITAS, M. T. A. (Org.). Memórias de professoras: História e histórias. S. Paulo/Juiz de Fora: Musa/EDUFJF, 2001. Além desses livros, a pesquisa gerou alguns capítulos de livros, artigos em periódicos e trabalhos publicados em anais de eventos.

2 Pesquisa: "Práticas sócio-culturais de leitura e escrita de crianças e adolescentes" (19971999) CNPq- Fapemig. Para conhecer mais sobre o conhecimento produzido nessa pesquisa, ver FREITAS. M. T. A; COSTA, S. R. (Orgs.). Leitura e escrita na formação de professores. S. Paulo/Juiz de Fora: Musa/EDUFJF/COMPED, 2002.

3 Pesquisa: "A construção/produção da escrita na internet e na escola: uma abordagem sócio-histórico-cultural” (1999-2001) CNPq-Fapemig. Sobre os achados dessa pesquisa, ver o livro: FREITAS, M. T. A.; COSTA, S. R. (Orgs.). Leitura e escrita de adolescentes na internet e na escola. Belo Horizonte: Autêntica Editora, 2005. Vários textos também foram publicados em anais de eventos e/ou EM periódicos discutindo sobre o tema pesquisado.

4 Pesquisa: "A construção-produção da leitura-escrita na internet e na escola: uma abordagem sócio-cultural (continuidade e desdobramentos)" (2001-2003), CNPq-Fapemig. Para conhecer um pouco mais sobre os achados dessa pesquisa, ver FREITAS, M. T. A. Sites construídos por adolescentes: novos espaços de leitura-escrita e subjetivação. Cadernos CEDES (UNICAMP). v. 1 p. 87-101, 2005.

5 Pesquisa "Letramento Digital e Aprendizagem na era da Internet: um desafio para a formação de professores" (2003-2006) CNPq-Fapemig. Para mais detalhes sobre esse 
trabalho, ver: FREITAS, M. T. A. Letramento Digital e a Formação de Professores. Caxambu. Anais da $28^{a}$ Reunião Anual da Associação Nacional de Pós-Graduação e Pesquisa em Educação / 40 anos da Pós-Graduação em Educação no Brasil: CD-ROM. 2005. FREITAS, M. T. A. Formação de professores e o uso do Computador e da internet na escola. Educação em Foco. Juiz de Fora: FEME, v. 12, n. 12, p. 251-270, dez. 2007/ fev. 2008.

6 Pesquisa: "Computador/internet como instrumentos culturais de aprendizagem na formação de professores em diferentes contextos educacionais de uma universidade federal" (2007-2010) CNPq-Fapemig.

7 Esse conceito está desenvolvido de forma específica, apresentando uma argumentação teórica embasada na perspectiva psicológica histórico-cultural, em FREITAS, M. T. A. Janela sobre a utopia: computador e internet a partir do olhar da abordagem históricocultural. Caxambu. Anais da 32ª Reunião Anual da Associação Nacional de Pós-Graduação e pesquisa em Educação. CD-ROM. 2009. Ver também: FREITAS, M. T. A. Computador/internet como instrumentos de aprendizagem: uma reflexão a partir da abordagem psicológica histórico-cultural. Anais do Simpósio Hipertexto e Tecnologias na Educação. Multimodalidade e ensino, 2., 2008, Recife. Anais eletrônicos... Recife, 2008. Disponível em: <http://www.ufpe.br/nehte/simposio2008/anais/Maria-TeresaFreitas.pdf>. Acesso em: 15 jul. 2009.

8 A cópia completa do relatório pode ser acessada em http://www.ets.org/research/icliteracy/ictreport.pdf.

9 A Universidade Aberta do Brasil foi criada em 2005, com o objetivo de aprimorar o sistema de educação a distância. Trabalha com a capacitação de professores da educação básica, com a formação continuada e com alguns cursos superiores.

Recebido: 06/11/2009

Aprovado: 09/08/2010

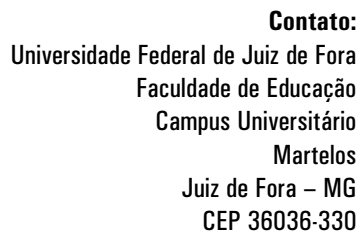

Educação em Revista | Belo Horizonte | v.26 | n.03 | p.335-352 | dez. 2010 